\title{
dossıê ASPECTOS DA DISCURSIVIDADE VISUAL DE UM JORNALISMO GRÁFICO: enunciação narrativa e testemunho visual em Le Photographe
}

Copyright $\odot 2015$ SBPjor / Associação Brasileira de Pesquisadores em Jornalismo

\author{
BENJAMIM PICADO \\ Departamento de Estudos Culturais e Mídia \\ Universidade Federal Fluminense
}

RESUMO - O artigo examina algumas das características que fazem de obras quadrinísticas exemplares de um sub-gênero designado como "jornalismo gráfico": caracterizado pela aproximação entre recursos visuais e discursivos das narrativas gráficas e pela exploração de universos temáticos associados à atualidade histórica e social, tais materiais suscitam discussões sobre critérios definidores das práticas do jornalismo, reconhecidos aí seus elementos, recursos, instituições e dispositivos. Interessa-nos observar as características de uma obra neste contexto, o álbum Le Photographe (GUIBERT, LEFĖVRE e LEMERCIER, 2009), observando aquilo que ilustra os regimes enunciativos e narrativos derivados das formas visuais empregadas nesta narrativa gráfica. Privilegiam-se abordagens metodológicas que discriminam a especificidade/integração de diferentes mídias (desenho, fotografia e composição gráfica), constituindo uma discursividade testemunhal das narrativas visuais contemporâneas: focalizam-se os esquemas narrativos da representação de ações e os jogos que demarcam as diferentes posições enunciativas da narração, pela oscilação entre formas desenhadas e fotografias.

Palavras-chave: Jornalismo em quadrinhos. Narrativas gráficas. Enunciação narrativa. Formas documentais. Le Photographe.

\section{ASPECTOS DE LA DISCURSIVIDAD VISUAL DE UNO PERIODISMO GRÁFICO: enunciación narrativa y testigo visual en Le Photographe}

RESUMEN - El artículo examina algunas de las características que designan los cómics como muestras de un subgénero etiquetado como "periodismo gráfico": se caracteriza por reunir recursos visuales y discursivas de narraciones gráficas, y la explotación de los universos de temas asociados con realidades históricas y sociales, tales materiales plantean discusiones sobre varios criterios para la definición de las prácticas periodísticas, como se reconoce en sus elementos básicos, recursos, instituciones y dispositivos. Estoy interesado en las características de una obra en particular, en este contexto, el álbum Le Photographe (GUIBERT, LEFÈVRE y LEMERCIER, 2009), con especial énfasis en la enunciación y regímenes narrativas de las formas visuales utilizados en esta obra. Preferencia se da aquí a los enfoques metodológicos que discriminan a la dialéctica entre la especificidad/integración de los diferentes medios de comunicación (dibujo, fotografía y composición gráfica), constituyendo una discursividad testimonio de narrativas visuales contemporáneas: me concentro en los esquemas narrativos de representación de las acciones y el juego que marca las diferentes posiciones discursivas de enunciación narrativa, a través de la oscilación entre el dibujo y formatos fotográficos. Palabras clave: Periodismo Gráfico. Narrativas Gráficas. Enunciación Gráfico. Formatos documentales. Le Photographe. 


\title{
ASPECTS OF VISUAL DISCURSIVITY IN GRAPHIC JOURNALISM: narrative enunciation and visual witness in Le Photographe
}

\begin{abstract}
The article examines some of the features designating comics as samples of a sub-genre labelled as "graphic journalism": characterized by bringing together visual and discursive resources of graphic narratives, and exploitation of topic universes associated with historical and social actualities, such materials raise discussions about several defining criteria for journalistic practices, as recognized in its basic elements, resources, institutions and devices. I am interested in observing the characteristics of a partícular work in this context, the album Le Photographe (GUIBERT, LEFÈVRE and LEMERCIER, 2009), with special focus on the enunciative and narrative regimes of visual forms used in this graphic narrative. Preference is here given to methodological approaches discriminating the dialectics between specificity/integration of different media (drawing, photography and graphic composition), constituting a testimonial discursivity of contemporary visual narratives: I concentrate on the narrative schemes of representation of actions and the game-like structure that marks the different discursive positions of narrative enunciation, through the oscillation between drawing and photographic formats.

Keywords: Graphic Journalism. Graphic Narratives. Graphic Enunciation. Documentary Formats. Le Photographe.
\end{abstract}

\section{PRÓLOGO}

Propomos examinar um conjunto de materiais próprios ao universo das assim chamadas "narrativas gráficas", com especial atenção a um segmento deste corpus no qual se apresentam problemas importantes para uma avaliação das práticas discursivas e regimes enunciativos do jornalismo: conferimos especial atenção a um segmento destas produções que tem recebido designações diversas, tais como "quadrinhos documentários" (ADAMS, 2008), "quadrinhos autobiográficos" (EL REFAIE, 2012) e "jornalismo em quadrinhos" (ROSENBLATT; LUNSFORD, 2011).

Nesta aproximação sobre o "jornalismo em quadrinhos", propomos analisar a obra coletiva Le Photographe (GUIBERT, LEFÈVRE e LEMERCIER, 2009): dentre as razões para esta escolha, destacamos o fato de que este álbum se localiza justamente em uma zona fronteiriça e cinzenta entre o registro documental e o testemunho jornalístico; esta é precisamente uma região que nos interessa, pois incorpora a arte dos quadrinhos a uma necessária autorreflexão crítica sobre o lugar cultural das práticas jornalísticas, especialmente em suas pretensões de mediação privilegiada da atualidade histórica. Para além disto, a obra em questão nos auxilia a pensar as possíveis inflexões críticas das práticas discursivas jornalísticas, em contraste com os cânones, instituições e regras deste campo profissional.

Fazemos tais requisições sobre o corpus a ser examinado, a partir de uma disjunção que propomos entre a obra em questão e 
outros exemplares mais "canônicos" deste sub-gênero emergente na cultura visual contemporânea: quando consideramos esta inflexão crítica de Le Photographe, entendemos que ela manifesta um caráter mais importante da definição do "jornalismo em quadrinhos" (ou, como chamaremos daqui para diante, "jornalismo gráfico") do que aquele massivamente atribuído à obra de Joe Sacco, por exemplo. No caso do artista maltês/americano, o recurso aos quadrinhos não chega a problematizar suficientemente os aspectos nos quais o apelo às formas pictóricas e gráficas afeta radicalmente a posição do jornalismo enquanto instância de pretensa mediação histórica - especialmente no destaque feito à figura do repórter, aspecto que caracteriza a construção dos lugares enunciativos nos álbuns de Sacco.

Muito embora sua obra represente uma novidade considerável, pelo fato de codificar as práticas jornalísticas em um novo meio, esta suposta inovação não ultrapassa o limiar desta adoção de dispositivos pouco usuais para a cobertura dos eventos de seu interesse: ainda se preservam intocadas aí muitas das questões sobre a inscrição de uma posição discursiva do relato jornalístico, enquadrando as significações do histórico de maneira predominantemente judicativa. Neste sentido, a obra de Joe Sacco reflete as mesmas aporias que caracterizam a posição tradicional das instituições, práticas e discursos do jornalismo, em relação aos regimes de mediação enunciativa e de auto-atribuição de uma compreensão histórica preferencial - aspecto sobre o qual muitos de seus comentadores não deixam de observar, por exemplo, na recorrência de certos regimes da escuta dos personagens de suas histórias.

[...] Aquilo que mais parece incomodar a Sacco em seu modo de escuta, mesmo (ou especialmente) quando ele está implicado nela, é o modo como a escuta obscurece a atividade dos sujeitos de suas histórias, tornando-os mais objetos de estudos do que agentes de sua própria história. É, em última análise, uma forma puramente instrumental de escuta, na qual repórter ouve, não para conhecer uma pessoa ou formar uma conexão relacional através do ouvir, mas para tomar posse desta experiência objectificada da pessoa, que assim não mais pertence a ele ou a ela [...]. Para o repórter, a escuta instrumental torna a pessoa e sua experiência uma mercadoria vendida sob a forma de notícia." (LUNSFORD; ROSENBLATT, 2011 , p.134).'

Em Le Photographe, por outro lado, as questões relativas aos posicionamentos enunciativos do relato factual não identificam esta instância discursiva exclusivamente com a figura do repórter (ou ainda, com a sombra institucional dos veículos mediáticos que ela representa): o fato de que se trata de uma obra tecida em sua 
autoria por uma tripla perspectiva (as do fotógrafo, do artista e do diagramador) produz efeitos dos mais interessantes na consolidação destas "posições actanciais" de mediação narrativa dos eventos. Nestes termos, a obra não reflete apenas três perspectivas discursivas ou autorais distintas, mas sobretudo uma partilha dos recursos e meios expressivos empregados na consolidação de certos efeitos de testemunho - que vão conferir o impacto mais notável que a obra é capaz de gerar em seus leitores. Portanto, não apenas uma variação das instâncias que efetuam o discurso narrativo, conduzindo os episódios em seus vários aspectos (de sucessão, de ritmo, de intensidade), mas igualmente o encontro (simultaneamente tenso e harmônico) entre o desenho, a fotografia e a ordenação gráfica dos materiais visuais e verbais.

Justamente por isto, nossa escolha pela obra de Guibert, Lefévre e Lemercier aponta igualmente para as estratégias analíticas que privilegiaremos, se refletindo também na estrutura argumentativa deste artigo, pelo modo como dividimos o tratamento que pretendemos oferecer à avaliação de Le Photographe ${ }^{2}$. Na primeira parte do artigo, avaliamos a propriedade da associação entre o "jornalismo gráfico" e determinadas práticas documentais da cultura visual contemporânea, especialmente no quesito do exercício programático (próprio aos marcos de uma estilística documental deste universo) de uma certa abertura e disponibilidade para as singularidades históricas, sociais e geográficas apresentadas nos quadrinhos e nas formas documentais; por exemplo, vinculamos a orientação enunciativa de Le Photographe a esta atitude, que alguns definem como "estética" (SHAEFFER, 2000), especialmente caracterizada pela articulação entre a receptividade da "escuta" e as práticas e "posicionamentos enunciativos" da narração.

$\mathrm{Na}$ segunda parte, desenvolveremos o problema das funções cumpridas pelos regimes da "enunciação gráfica" (BAETENS, 2001) que se atualizam pela combinação de desenho, fotografia e composição visual, tanto no que respeita os regimes da ação que compreendem as peripécias da missão do fotógrafo junto à equipe dos Médicos sem Fronteiras ${ }^{3}$, quanto no tocante às diferentes posições enunciativas inscritas na conjunção destes materiais significantes - e que implicam outras funções da enunciação narrativa, mais associadas à dimensão pragmática da mediação de uma realidade social e histórica e menos à de uma mera condução discursiva dos eventos narrados. Neste segmento do texto, trabalharemos a enunciação gráfica nesta dupla dimensão de promotora dos "ritmos" e "tensões" próprios da evolução narrativa, mas também em 
seu aspecto de valoração de um regime de acolhida das singularidades históricas, sociais, geográficas e pessoais que emergem na obra.

$\mathrm{Na}$ última parte do artigo, colocaremos em perspectiva a significação de todos estes procedimentos expressivos e estratégias discursivas em Le Photographe, na perspectiva de uma hipótese sobre os modos em que o "jornalismo gráfico" problematiza efetivamente certas condições de uma mediação histórica privilegiada que caracterizaria o exercício profissional da cobertura da atualidade: neste contexto, nos restituímos a determinados problemas da função atribuída à imagem na cobertura jornalística, caracterizando o fotojornalismo enquanto campo de provas de uma permanente instalação da imagem sobre a "crise de seus usos" (POIVERT, 2009; PICADO, 2014).

\section{1 “JORNALISMO GRÁFICO” E PRÁTICAS DOCUMENTAIS NA CULTURA VISUAL CONTEMPORÂNEA}

Avaliamos com considerável preocupação a indistinção com a qual se sintetizam o caráter mais "subjetivo" do registro enunciativo de certas narrativas gráficas e o aspecto assumidamente "documental" que se atribui às mesmas, como subscrição a um gênero discursivo particular: esta junção apressada entre subjetividade formas documentais acaba por descomprometer a análise dos quadrinhos documentais com respeito aos diferentes registros nos quais a função testemunhal do discurso confere pertinência àquilo que é da ordem dos distintos regimes enunciativos da história, nas formas e recursos próprios às narrativas gráficas.

Em nosso exame, é fundamental reconhecer a imanência dos regimes discursivos caracterizados pela articulação entre enunciação subjetiva e a mediação testemunhal dos acontecimentos. É no contexto mesmo deste jogo entre enunciação explicitada e mediação histórica que poderemos caracterizar as formas específicas de uma atividade jornalística exercitada através dos recursos e dispositivos visuais e gráficos - sem que tenhamos que pagar o necessário (e indevido) tributo de uma assimilação automática do "jornalismo gráfico" aos registros da enunciação que definem a estilização de uma auto-reflexividade discursiva no plano literário, por exemplo.

Precisamos retomar este problema, precisamente a partir das considerações sobre o que há de mais específico ou imanente no regime discursivo que consagra a abordagem jornalística, no interior das narrativas gráficas. Em primeiro lugar, partamos das considerações sobre o problema da explicitação da instância enunciativa do discurso 
reportativo, que é mais característico de certos gêneros jornalísticos. Já indicamos o modo como as obras de Joe Sacco expõem sua posição mesma de mediador da atualidade histórica, com os modos em que esta "posição de discurso" (BENVENISTE, 1966) é funcionalizada, especialmente na diferença que ela faz com respeito a auto-reflexividade nos gêneros literários da modernidade (por sua vez refletidas no gesto autobiográfico de certas narrativas gráficas). Precisamos agora extrair algumas possíveis consequências desta clivagem sugerida entre a "autobiografia" e os regimes "históricos" do discurso, de modo a encontrarmos o lugar em que os registros jornalísticos das narrativas gráficas possam ser melhor enquadrados analiticamente.

Há um aspecto importante que nos auxilia a desenvolver este ponto da enunciação histórica, própria ao discurso jornalístico: ele implica em que pensemos na continuidade que atravessa a classificação do "jornalismo gráfico" e a dos "quadrinhos documentários". Na verdade, trata-se de algo que designamos alhures como práticas documentais na cultura visual contemporânea (FRANÇA; PICADO; LINS, 2013), tipificando uma extensão considerável de registros discursivos, estratégias narrativas e de dispositivos mediáticos, por sua vez associados às formas visuais e às funções documentais que elas assumem (enquanto fonte, arquivo ou vetor testemunhal), em diferentes contextos da mediação de realidades sociais e históricas.

Em todas estas práticas documentais, encontra-se uma inflexão das imagens que é marcada por uma presumida posição do espectador, este último concebido como eixo articulador dos regimes visuais destas formas documentárias - passando pela construção dos vários posicionamentos de um sentido de testemunho que é mediado pela própria forma visual: dentre os elementos que aí operam, encontramos tanto a produção e explicitação dos "dispositivos da interação" entre o cineasta e seus personagens, pelo recurso da voz em off e pelo estabelecimento dos protocolos conversacionais (LINS, 2011), a constituição de uma "cenografia documental", através de uma concepção "topográfica" dos espaços da filmagem (FRANÇA, 2009), ou ainda pela constituição dos "vetores de imersão" (SCHAEFFER, 1999) pelos quais a imagem pode instaurar as várias dimensões de sua experiência como aspectos de um "testemunho vicário" da cena (PICADO, 2011).

Transposta para os quadrinhos, esta perspectiva implica um modo de pensar os regimes da enunciação que caracterizam o escopo das obras definidas como "jornalísticas", não apenas na relação com o universo factual das histórias, mas sobretudo por um certo 
conjunto de atitudes próprias à posição mediadora do repórter. Neste contexto, ainda que explicitada enquanto instância enunciativa da condução do discurso, a posição ocupada por Joe Sacco não pode ser imediatamente identificada como sendo a de um narrador privilegiado dos acontecimentos, pois a maior parte daquilo que construímos enquanto sentido factual dos eventos que compõem suas obras se origina efetivamente de seu encontro com as vozes das testemunhas e não a partir de sua enunciação mesma de repórter. Em decorrência disto, a posição actancial deste mediador é atualizada a partir de uma carga considerável de perplexidade, inquietação, dúvidas sinceras e até mesmo de certa ingenuidade em face da realidade.

Neste sentido, a construção da posição discursiva do repórter que articula diferentes vozes testemunhais implica, de modo pragmaticamente mais determinante, a condição fundamental de uma constitutiva disponibilidade para a escuta. Já mencionamos acima a idéia de um tipo de "escuta gráfica" (LUNSFORD; ROSENBLATT, 2011), caracterizada não apenas pelas atitudes próprias do repórter que colhe informações em campo, mas sobretudo do artista que tenta recriar estas condições de seu encontro com a realidade, nas formas que o desenho e a organização gráfica do álbum propiciam e preservam para o leitor. Há ainda quem destaque a qualidade de um "silêncio gráfico", outro aspecto da enunciação narrativa própria dos "quadrinhos jornalísticos": a perplexidade aparente de certos momentos destas obras - em que o repórter ou narrador apenas contempla uma realidade - aporta uma inflexão crítica com respeito à normatividade de um presumido "cosmopolitismo" do jornalismo, em face dos universos de alteridade geográfica e histórica.

[...] Contra o moralismo banal das reportagens conversacionais, Sacco confronta sua própria marca de [...] 'suspeita' cosmopolita: revelada através de conversas amigáveis com amigos locais na Bósnia e na Palestina, ainda assim ele captura a subjacência de ambivalência e absurdo da guerra, cristalizada in painéis silenciosos de grande escala, trazendo ao primeiro plano a crua escala do desastre e privação, com o olhar panorâmico de um Hieronymus Bosch, capturando fisionomias individuais e eventos aparentemente insignificantes que poderiam ocorrer [...] 'a um centímetro ou dois de um Brueghel'” (BANITA, 2013, p.56-57).

Esta mesma atitude caracteriza igualmente aquilo que certos autores têm identificado com as tendências mais marcantes do documentário fílmico nos últimos 50 anos, pelo menos, especialmente a partir das vertentes do "cinema direto" norte-americano e do "cinemaverdade" francês: na tradição do cinema documentário que se restitui à influência exercida pelas obras de Jean Rouch e Frederick Wiseman 
(para ficarmos apenas em dois casos mais luminares), pressente-se este aspecto de uma disponibilidade pré-judicativa em face dos assuntos abordados pelo registro visual, preservando na imagem esta mesma qualidade própria do encontro entre o cineasta e uma realidade.

\section{ENUNCIAÇÃO GRÁFICA E EFEITOS DE TESTEMUNHO NO "JORNALISMO GRÁFICO"}

No contexto específico do estudo das narrativas visuais e audiovisuais, a questão dos regimes específicos da enunciação constitui um desafio heurístico de não pouca monta: o universo visual impõe dificuldades para a análise da narração, na medida em que seus principais meios manifestam-se com uma tal "transparência" que acaba afetando os regimes da atenção pelos quais acompanhamos a enunciação. Diferentemente dos recursos pelos quais a narrativa literária não apenas indica uma instância enunciativa, mas é interditada a obscurecê-la, a narrativa fílmica é atravessada de uma "impessoalidade" (METZ, 1991) constitutiva, aspecto que conduziu as teorias da narrativa a delimitar este problema da enunciação fílmica à funcionalidade dos recursos próprios à arte cinematográfica, especialmente na tradição do estruturalismo semiológico. ${ }^{4}$

Um importante aspecto das teorias da enunciação fílmica é que a definição de seu objeto resulta de um esforço por especificar na estrutura textual de uma obra fílmica aqueles segmentos nos quais a ação pode ser restituída ao "ato" através dos qual os eventos são representados narrativamente: a enunciação fílmica se examina quando certos elementos constitutivos das formas cinematográficas (planos, montagem, focalizações) são funcionalizados não apenas para render os acontecimentos, mas também para delinear as posições discursivas através das quais os eventos são valorizados ou predicados, em aspectos variados (morais, psicológicos, dramáticos).

Nas narrativas gráficas, esta questão dos regimes enunciativos se apresenta igualmente em estado embrionário: do mesmo modo que nas teorias fílmicas, há uma tendência a assimilar os atos discursivos da enunciação ao conjunto dos dispositivos através dos quais a história é apresentada; do mesmo modo que na análise fílmica, em que a funcionalidade da enunciação é definida pelos atos de "mostrar" e não pelo "dizer" (GAUDRÉAULT e JOST, 1990), a aplicação dos preceitos narratológicos ao universo gráfico confere 
alguma especificidade aos dispositivos específicos dos quadrinhos, na relação com a enunciação narrativa que the é mais própria.

Há um aspecto da discursividade narrativa do universo gráfico que se deixa assimilar ao caráter próprio do "ato" que tipifica sua enunciação - e que é da mesma ordem de uma "mostração". Contudo, há um aspecto que diferencia os quadrinhos e que não se define propriamente pela particularidade mediática de sua apresentação: segundo certos comentadores, este aspecto da enunciação dos quadrinhos se revela apenas nas interações que as formas gráficas promovem com o horizonte da leitura e da recepção; pois é neste contexto que Jan Baetens destaca a importância da noção de "enunciação gráfica", originária das teorias de Philippe Marion (MARION, 1993), implicando aí uma valorização dos aspectos estilísticos que formam o desenho e a composição gráfica da página, definidos enquanto "traços" da singularidade discursiva através da qual a história é narrada.

\begin{abstract}
"Marion [...] alega que, em primeiro lugar, é para o leitor que toda obra é destinada, e, em segundo lugar, que também é para o leitor que o trabalho do artista gráfico é refeito. Este é um ponto essencial: Marion argumenta que o leitor tem a capacidade de refazer, para reconstruir, ou pelo menos para re-experimentar o trabalho enunciativo produzido pelo autor, pela simples razão de que esta produção é baseada em gestos e mecanismos que cada leitor conheceu e praticou enquanto criança, mas que esqueceu enquanto adulto. (BAETENS, 2001: p.149,150).
\end{abstract}

Esta questão dos regimes da "enunciação gráfica" é central na análise que faremos de Le Photographe, em especial na articulação entre a posição discursiva (a admissão de uma instancia subjetiva da narração) e os modos de reconhecimento da obra pela leitura (sua inscrição ao gênero do "jornalismo em quadrinhos"). Ela se manifesta na própria unidade gráfica do álbum, caracterizada por uma singular valorização dos modos de integração entre o desenho e as seqüências visuais de Emmanuel Guibert e a exposição das folhas de contato fotográficas, originadas do trabalho em campo de Didier Lefèvre.

De fato, ao examinarmos as páginas dos volumes da obra, notamos a assimilação da composição gráfica das páginas à apresentação física das folhas de contato em sua superfície. Antes de mais nada, na medida da apropriação que a concepção gráfica da página faz desta exposição dos materiais originais da fotografia, confere-se uma impressão visual à paginação que é marcada pela predominância de uma ordenação vetorial das seqüências visuais, por sua vez própria à linearidade das tirinhas desenhadas, ainda que 
com algumas variações de escalas e tamanhos - tudo isto fortemente orientado pelo papel articulador dos recursos fotográficos da obra, na medida em que favorecem determinados regimes vetoriais da leitura.

Por outro lado, esta correlação entre dois distintos materiais significantes (o complexo de desenho e tirinhas e a fotografia em folhas de contato) é igualmente responsável pelo estabelecimento de determinados efeitos da condução discursiva da história, aspecto que aponta para o preciso objeto de nosso exame: nos vários regimes desta enunciação que se estabelecem nos enlaces das formas desenhadas e da fotografia (gestado pela mediação da concepção gráfica da paginação), destacamos aqueles que orientam a condução discursiva no sentido em que sua leitura é constituída pelo reconhecimento dos aspectos jornalísticos/documentários - aqueles que inscrevem a obra a um gênero testemunhal de relato histórico.

Neste último sentido, notamos primeiramente como a organização gráfica que permeia o jogo entre desenho e fotografia se caracteriza pela oscilação iterativa entre estes materiais, indicando uma igual alternância da "focalização" narrativa: de modo geral, esta flutuação entre perspectivas da orientação discursiva atribui às formas desenhadas uma posição mais "externa" do acompanhamento da história, reservandose para a emergência das formas fotográficas a predominância de uma "focalização interna", o que se explicita particularmente nos modos como o fotografo é exibido no desenho, acompanhado de um recitativo que representa sua própria voz, manifestando suas questões sobre a jornada da equipe médica e remetendo suas possíveis respostas ao ato de fotografar - seguindo-se daí o resultado da operação, na forma de um registro fotográfico (fig. 1):
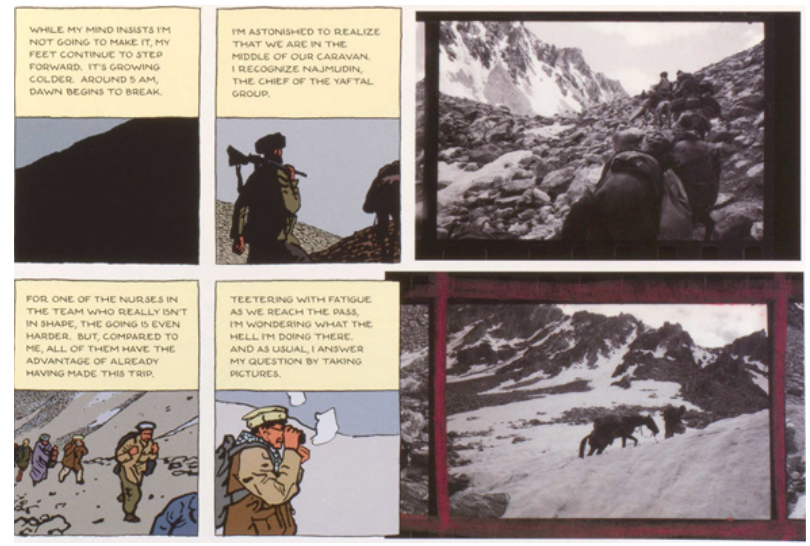

1. The Photographer (detalhe, pé da página) 
Neste mesmo contexto, cabe explorar igualmente os modos nos quais esta alternância entre formatos visuais e posições enunciativas instaura efeitos de leitura diversos, uma vez que ocorram no interior de uma mesma página, ou então no intervalo que compreende a atenção da leitura entre duas páginas abertas ou ainda no espaço entre uma página e o outra que se dobra mais adiante. De um modo igualmente geral, nota-se que a variação entre desenho e fotografia, uma vez ocorrendo no interior de uma mesma página, cumpre funções tais como as da objetivação de personagens ou de situações cuja descrição é função dos recursos gráficos dos "recitativos" - aquele segmento do sistema dos quadrinhos que se define pelas inscrições textuais dos assuntos de interesse da história (Fig. 2).
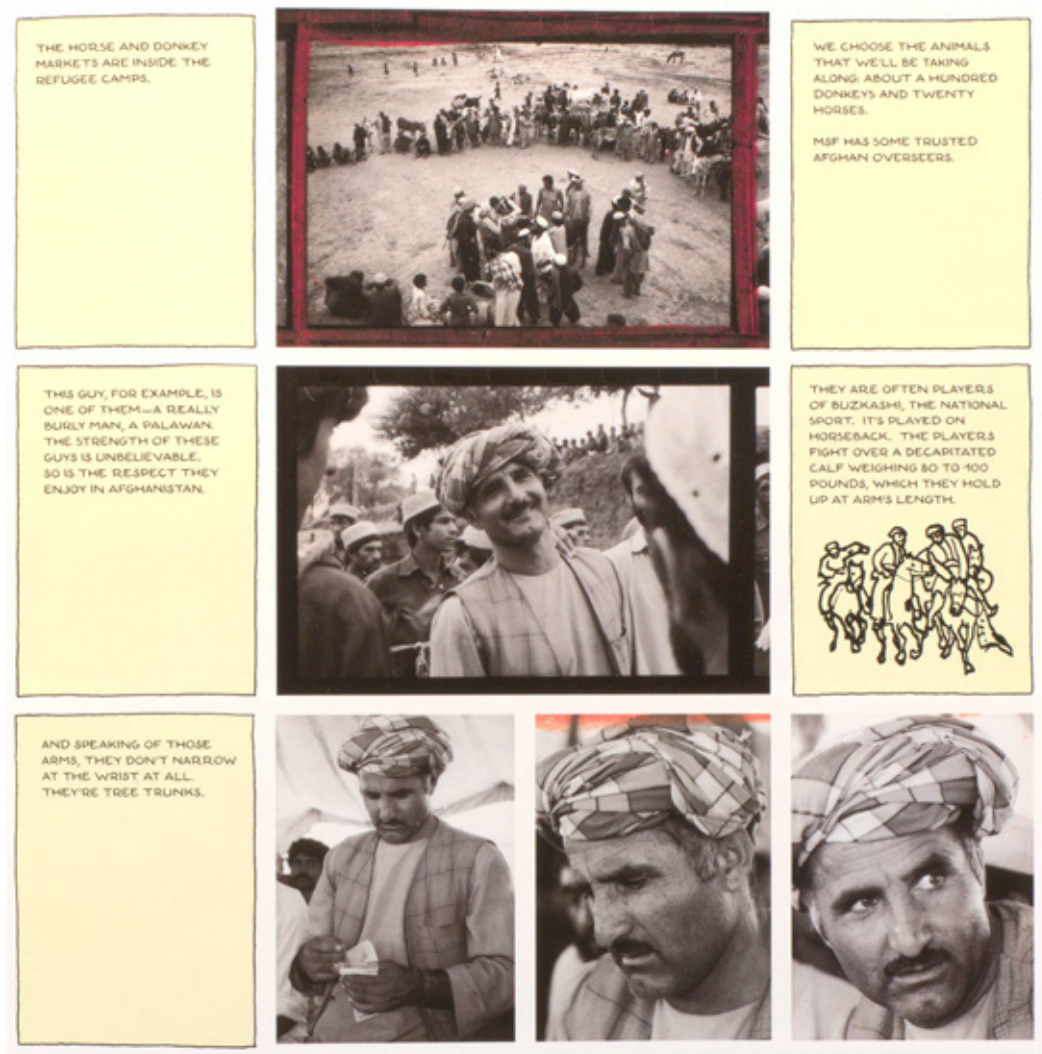

2. The Photographer p. 13 (detalhe, $3 / 4$ superior da página). 
Outra instância desta funcionalidade iterativa entre desenho e fotografia é aquela na qual a propriedade destas interações mais intensas do fotógrafo com os sujeitos de sua exploração assumem um aspecto central para a significação global da história: são os contextos em que a figura de Didier Lefèvre se implica enquanto agente mediador de tudo aquilo que assume importância - mesmo que mais afetiva ou pessoal - para a compreensão dos valores da missão médica. Estes são recursos que caracterizam as etapas iniciais da história, quando o fotografo ainda busca inteirar-se melhor de sua posição no interior do conjunto de fatores a se registrar do trabalho da equipe (Figs. 3 e 4), mas que ressurgem eventualmente em situações de repouso das peripécias da missão - quando o fotógrafo pode assumir uma postura mais contemplativa, em relação aos espaços em que se encontra ou em face dos indivíduos com os quais se encontra (Fig. 5).

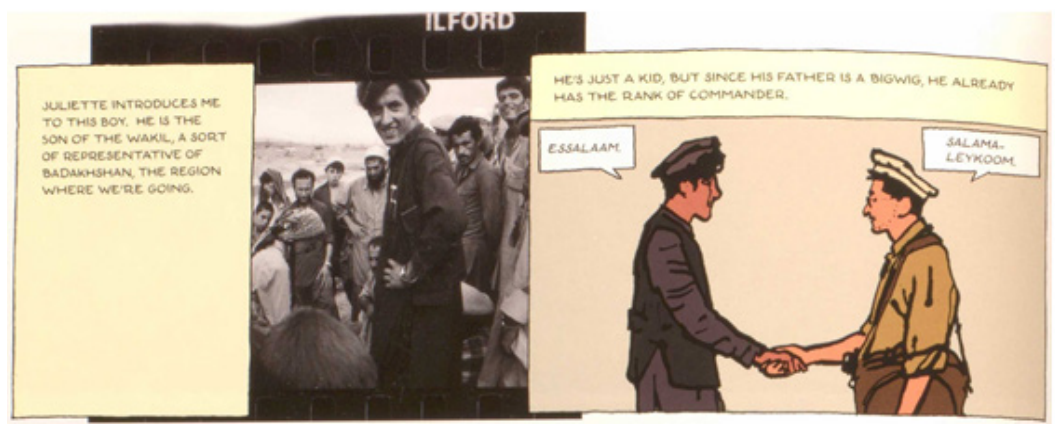

3. The Photographer p. 16 (detalhe, 1/4 superior da página).

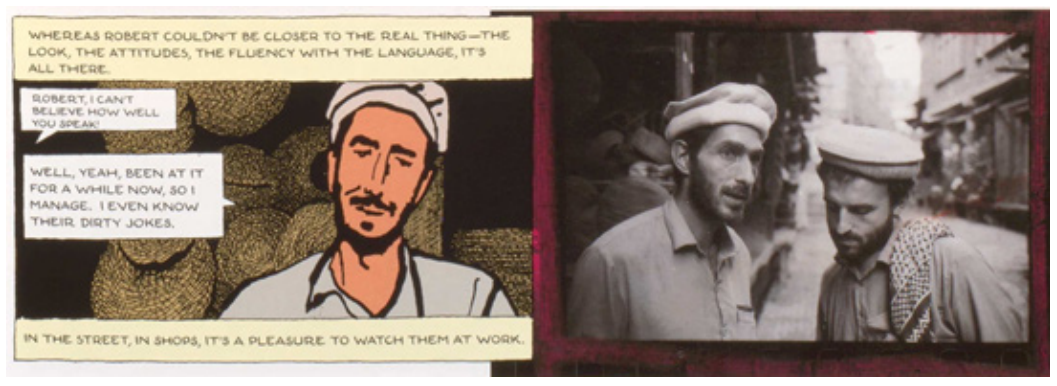

4. The Photographer p. 17 (detalhe, $1 / 4$ inferior da página). 

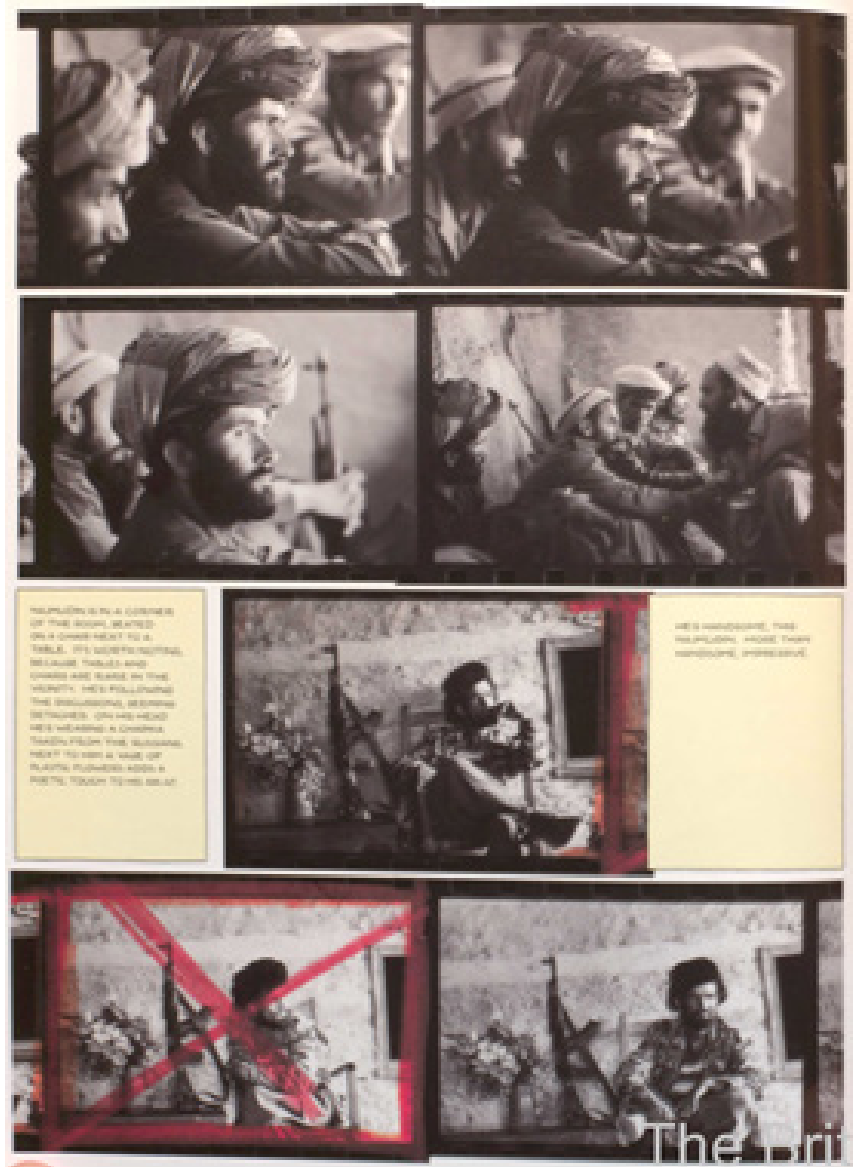

5. The Photographer p. 44 (página inteira).

Distintos são os casos em que a negociação entre desenho e fotografia acontecem no intervalo que separa dois domínios distintos do percurso vetorial da leitura, seja no âmbito de uma página dupla aberta (em que o lapso se estabelece entre a parte final da página à esquerda e a força ascendente que conduz o olhar para o alto da página à direita), ou então no vazio que se impõe entre o fim da página à direita e o prosseguimento da leitura, na página seguinte a ser virada. De modo geral, esta negociação entre materiais significantes é frequentemente associada à produção de um certo suspense instaurado por entre dois regimes de focalização, como se o desenho se construísse na preparação de um assombro narrativo, propiciado pela introdução dos recursos visuais da fotografia - o que é conotado pelas diferenças de escala na apresentação 
destes materiais, com seqüências de pequenos quadros desenhados, ao fim de uma das páginas, com um arremate da seqüência na página seguinte, com a exibição de fotografias em grande escala (Fig. 6 e 7).
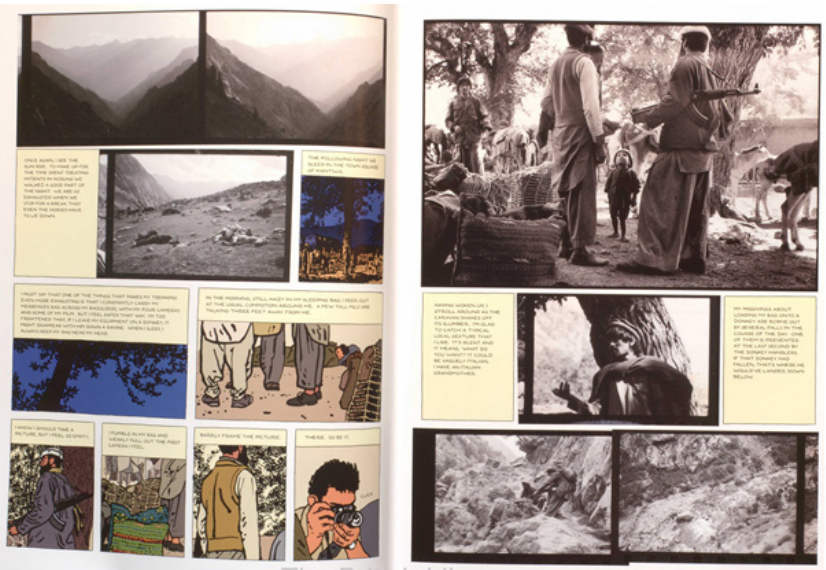

6. The Photographer p. 58 e 59 (páginas inteiras).
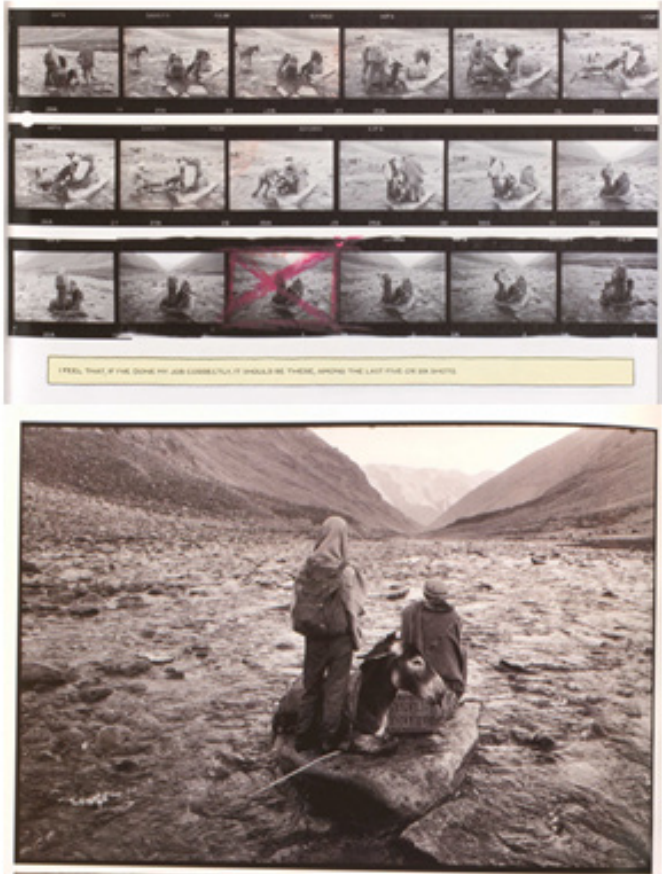

7. The Photographer p. 73 e 74 (metades inferior e superior, respectivamente). 
Um aspecto particularmente importante para esta análise dos jogos entre formas visuais e posições enunciativas nos quadrinhos se encontra no modo como estes procedimentos conferem à instância da leitura as condições para o reconhecimento dos padrões discursivos nos quais se pode estatuir a mediação histórica, por sua vez própria às práticas jornalísticas. De saída, há uma modulação dos acontecimentos narrados que caracteriza os regimes próprios a certos gêneros da reportagem vinculados às formas documentais, especialmente naquilo que implica certas modalidades da interação entre a mediação discursiva do repórter e os testemunhos visuais ou verbais dos assuntos.

Em Le Photographe, isto é particularmente derivado do modo como o fotografo se aproxima de determinados contextos da ação mais cotidiana da equipe dos médicos ou da comitiva que lhe dá apoio no percurso, margeando as montanhas da região norte do Afeganistão. Ao valorizar estas peripécias (a partir de um regime estético de proximidade e de observação), a combinação dos recursos de desenho e fotografia (gerando efeitos de "enunciação gráfica") muito faz lembrar uma certa atitude do cinema documentário contemporâneo, ainda que tingida de um sabor mais sensacional e afetivo desta proximidade. Por outro lado, estes procedimentos - especialmente o modo como os recursos fotográficos são inscritos na obra - implicam o valor de certos regimes duracionais de construção da enunciação narrativa. Estes, mais uma vez, sugerem as linhas de proximidade entre a discursividade jornalística, de um lado, e as práticas documentais da cultura visual contemporânea, de outro.

\section{A ENUNCIAÇÃO GRÁFICA E A ORDEM ACONTECIMENTAL DO "JORNALISMO GRAFICO"}

Nos avizinhamos, então, dos procedimentos da enunciação gráfica em Le Photographe e do modo como são reconhecidos na relação com o gênero discursivo dos "jornalismo gráfico". Caracterizados pelo jogo iterativo entre as formas desenhadas e a apresentação vetorializada do registro fotográfico (valorizando a ordem sequencial das relações do fotografo com os universos da história manifestação), vimos anteriormente que a organização gráfica das páginas apresenta os episódios não apenas como 
sequências acontecimentais, mas sobretudo enquanto figurações dos posicionamentos do fotógrafo em face dos eventos. De nosso ponto de vista, contudo, a melhor maneira de examinar este processo é também a de avaliar o regime das ações que é privilegiado nesta obra, em aspectos que sinalizam a predileção por eventos de uma natureza bem particular, sobre os quais discorreremos a seguir.

Um indicativo importante da inscrição das folhas de contato fotográficas no corpo desta obra é o fato de que esta apresentação atualiza um aspecto dos processos de gênese da imagem fotográfica pouco tematizado na maior parte daquelas teorias que insistem em um caráter da significação indexical da fotografia fortemente derivado do automatismo de seu dispositivo. De uma maneira geral, aquilo que encontramos nas folhas de contato não é apenas sugestivo dos contextos de uma agência fotográfica, mas também resulta em uma exposição destes contextos da movimentação do olhar do fotógrafo menos marcada pela sinédoque com a qual as teorias mais tradicionais da fotografia atribuem sua significação mais saliente, aquela da ostensão do mundo visual.

No caso de Le Photographe, uma boa porção destes contatos representa situações de um caráter bem menos sensacional do que aquelas em que fotografias instantâneas sintetizam eventos dinâmicos: neste episódios da evolução do fotógrafo junto à equipe médica, fica patente este caráter menos intenso ou sintético das seqüências de eventos aos quais seu olhar se dedica. São acontecimentos da rotina do trabalho desta missão, tais como nos instantes que antecedem o início desta aventura, quando a equipe organiza os materiais da viagem, a partir de uma disciplina e princípio próprios (Fig. 8). Quando acompanhamos a ação dos ajudantes locais que tentam alojar os animais que levarão a maior parte da carga da missão em carroças, a serem levadas a um ponto de encontro próximo da fronteira paquistanesa (Fig. 9); ou finalmente quando o fotografo observa Juliette, uma das líderes da comitiva médica, em seus cuidados matinais com a própria aparência, arranjando o cabelo, pouco antes da retomada da viagem (Fig. 10). 


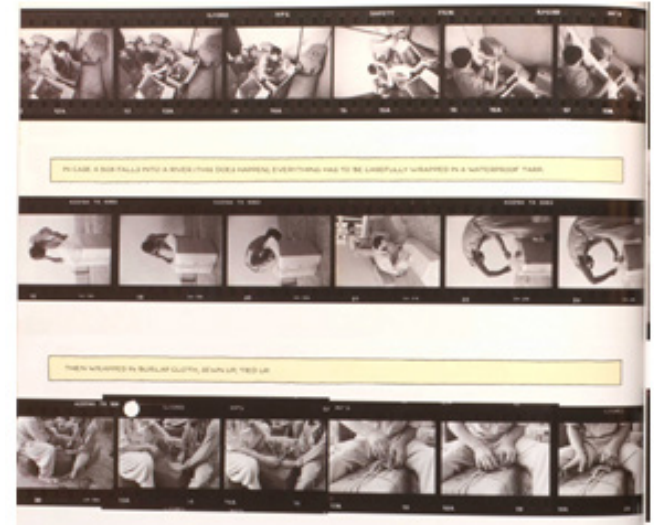

8. The Photographer p. 8 (detalhe, 3/4 inferior da página).
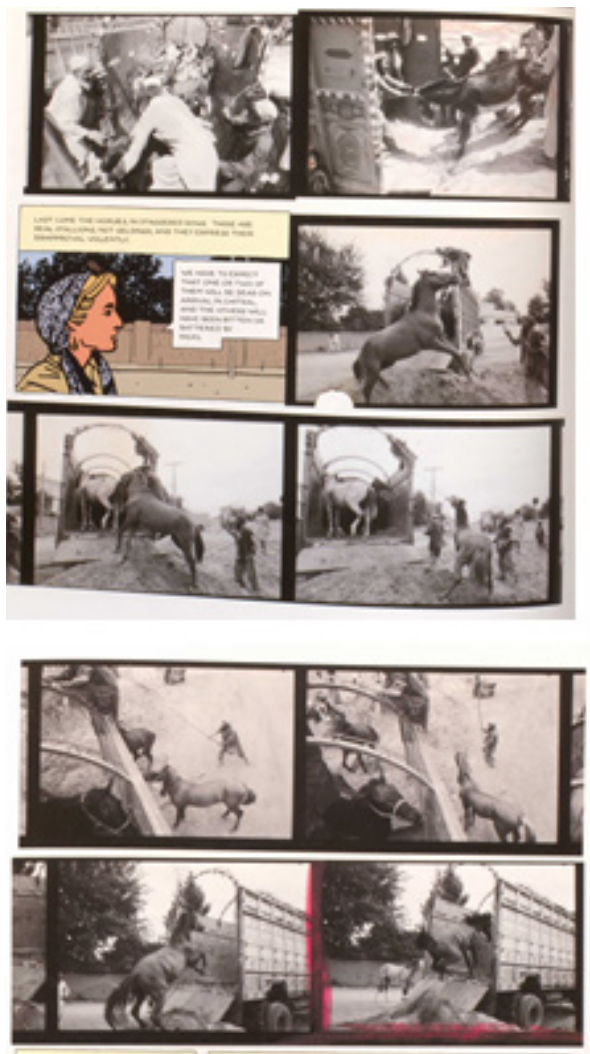

9. The Photographer p. 32 e 33 (metades inferior e superior, respectivamente). 

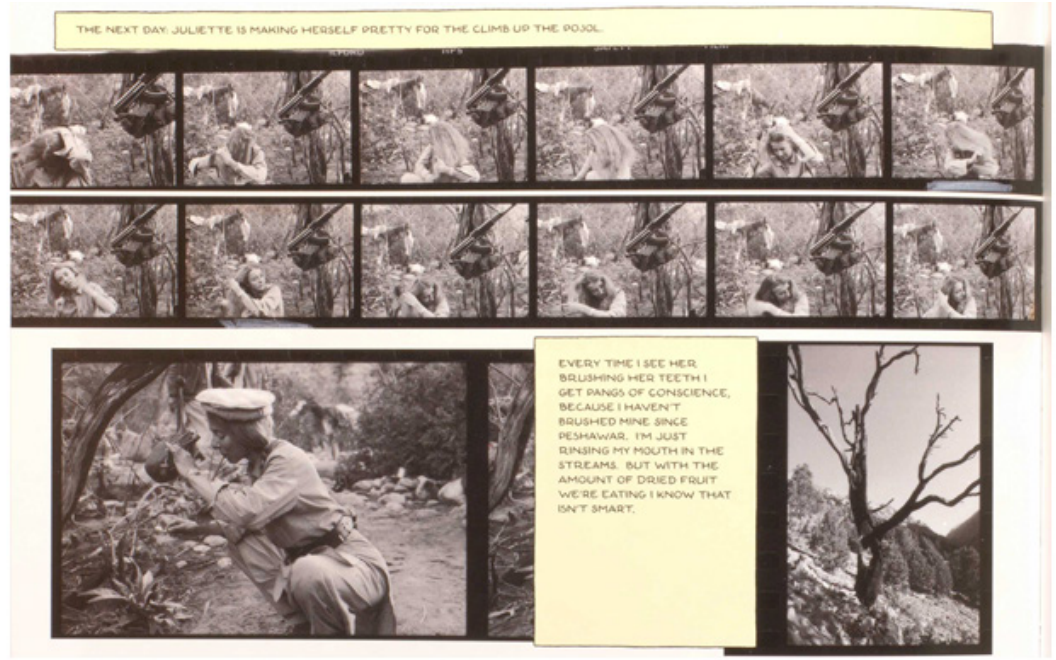

10. The Photographer p. 62 (detalhe, metade superior da página).

De um ponto de vista propriamente narratológico, estes são momentos de menor intensidade dramática, que servem genericamente (ao menos no contexto mais canônico das narrativas ficcionais) para condicionar o comportamento dos agentes a seu caráter preciso de motivação, em vários de seus aspectos. Barthes designava este segmento das funções narrativas como sendo as "catálises", caracterizando-as por esta sua aparente insignificância com respeito a outros segmentos da história nos quais determinadas situações são propriamente resolvidas ou concluídas - estes últimos sendo os "núcleos" (BARTHES, 1966).

$\mathrm{Na}$ perspectiva em que vislumbramos estes segmentos da rotina acional dos personagens em Le Photographe, a presença destes eventos (que, nos dizeres de Barthes, possuem uma função meramente "cardinal" para a economia global da história) assume uma importância central, na medida em que a ordenação da história para o horizonte da leitura não implica a suposição de que estes segmentos necessitem se correlacionar com uma maior frequência de momentos de uma carga dramática mais pronunciada. No modo como estes eventos ordinários são introduzidos à história (por meio da organização gráfica que valoriza os esquemas sensório-motores das sequências expostas nas folhas de contato), o que se coloca em jogo é precisamente o reconhecimento dos regimes textuais 
que inscrevem a experiência da leitura a uma perspectiva mais "documental" ou "jornalística" desta narrativa.

É nestes episódios que podemos ressentir que a organização gráfica dos acontecimentos nas páginas de Le Photographe acusam mais fortemente a mediação testemunhal que confere à discursividade jornalística deste formato gráfico suas linhas de continuidade com as formas documentais contemporâneas. São momentos tais como aqueles em que a missão médica chega a uma pequena localidade afegã e é chamada a socorrer uma anciã que é diagnosticada com um tumor em seu pé direito. O olhar fotográfico sobre a ação que os médicos desencadeiam para remover este câncer combina aspectos de um olhar mais guiado pelo sentido do "choque" do fotojornalismo, mas também combinando-o com um senso de "deslocamento" próprio ao documento visual, que também opera pela exibição dos detalhes aparentemente insignificantes deste drama (Fig. 11).

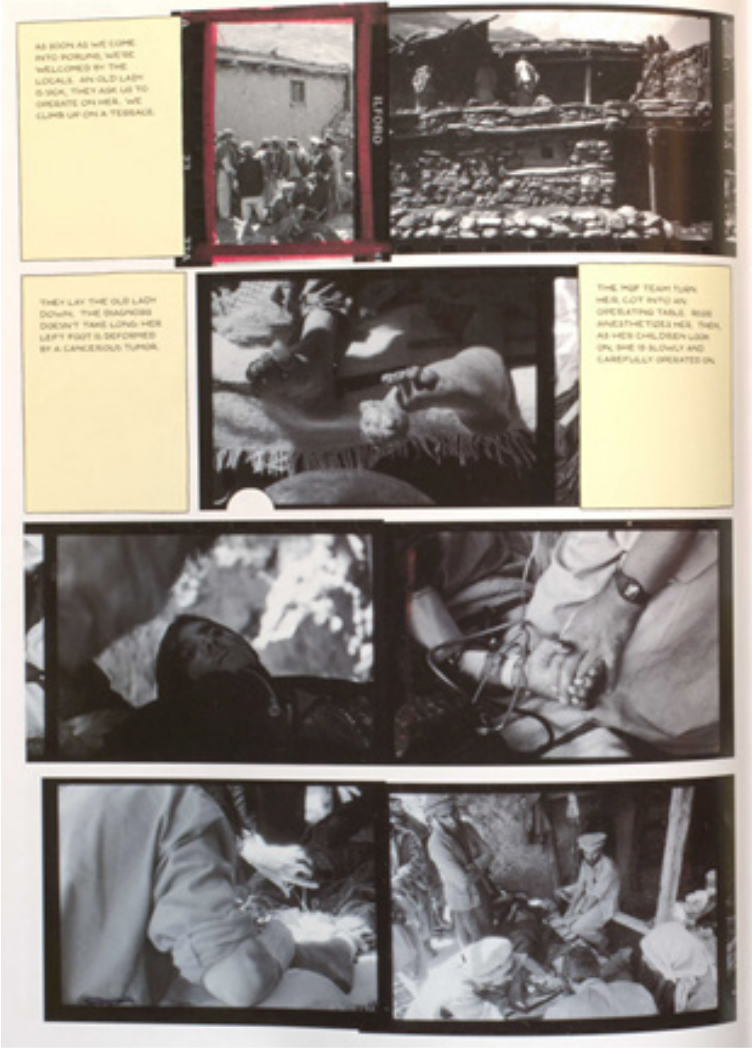

11. The Photographer p. 54 (página inteira). 
Outro aspecto deste distanciamento da atenção visual sobre as ações da missão dos médicos é particularmente notável no modo como o fotógrafo se mostra sensível àquilo que acontece em torno dos movimentos e peripécias da equipe, e que compõe a rotina de um país dilacerado pela guerra, que passa lateralmente pelo percurso que a missão faz pelo território afegão. Com alguma frequência, esta presença da fotografia - exibindo certos contextos de uma ação mais cotidiana - é empregada para nos confrontar com todos aqueles que, atingidos pela guerra, fogem para outros recantos do pais, passando pela missão médica, sempre no sentido contrário de seu percurso (Fig. 12). Ou ainda, quando é a paisagem deslumbrante de alguma parte do Afeganistão que se destaca para o olhar fotográfico, mesmo quando as partes da travessia sobre estes segmentos implicam toda sorte de riscos para a equipe - em função de serem feitas durante o dia, em zonas de conflito entre as forças afegãs e russas, sempre sob a vigilância estrita dos atiradores de elite de ambas as partes (Fig. 13).

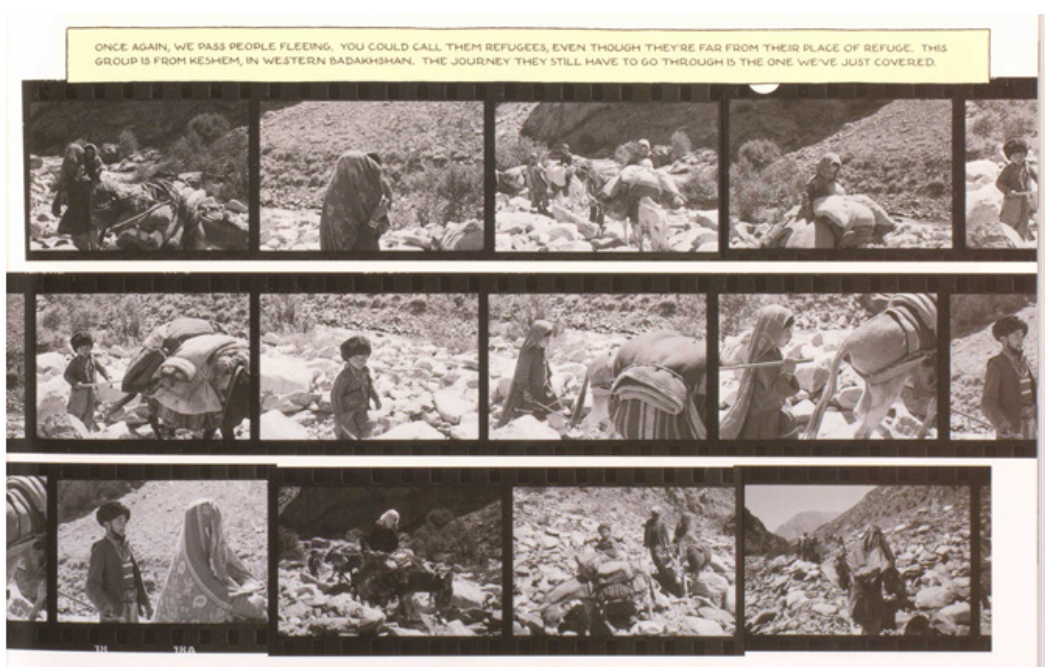

12. The Photographer p. 69 (detalhe, metade inferior da página). 

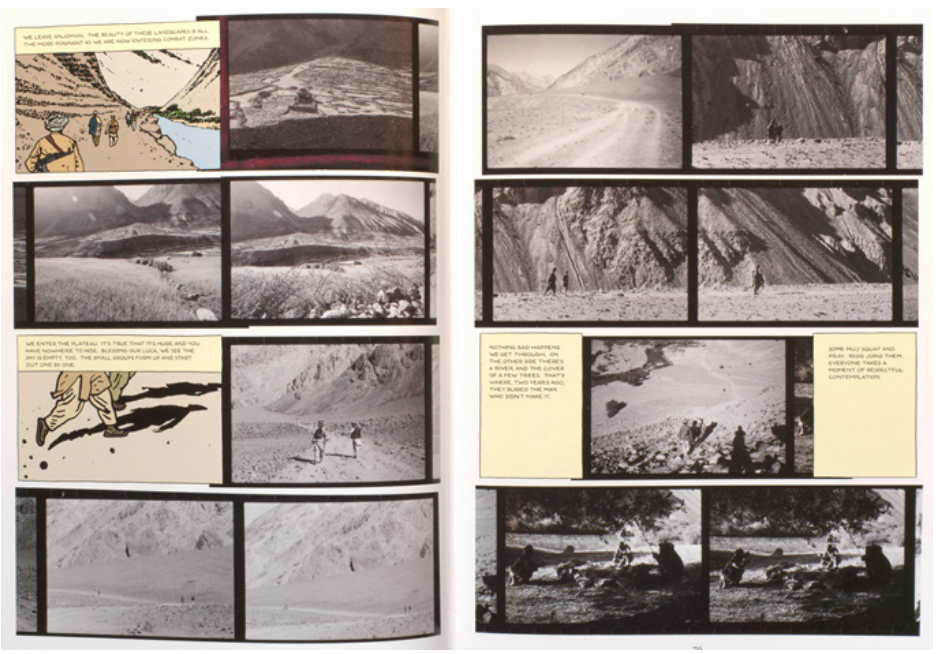

13. The Photographer p. 78 e 79 (páginas inteiras).

Um aspecto a se destacar desta organização discursiva na qual Le Photographe se torna reconhecível como obra de "jornalismo gráfico" (e bem especialmente nesta condição da inflexão crítica sobre as pretensões jornalísticas de mediação privilegiada do histórico) é precisamente aquele que decorre do emprego desses elementos visuais e gráficos. Eles implicam não apenas uma novidade dos recursos e dispositivos constitutivos das práticas documentais na cultura contemporânea, mas justamente o horizonte ético destas práticas discursivas através da imagem. A "enunciação gráfica" que atravessa as formas desenhadas, a fotografia e a organização gráfica em Le Photographe apresenta importantes questões para uma reflexão sobre a discursividade visual inscrita aos processos de mediação histórica, recolocando o sentido ético destes diferentes posicionamentos enunciativos e a importância atribuída a um certo distanciamento pré-judicativo destes exercícios discursivos - principalmente em face das singularidades sociais, históricas, geográficas e humanas apresentadas graficamente, no contexto das peripécias desta missão médica no Afeganistão.

Os modelos narratológicos que privilegiam o sentido mais ordinário dos percursos desta missão necessitam se articular com o horizonte ético de um posicionamento discursivo que exercita valores documentais da mediação jornalística da realidade, precisamente por manter sempre vivas (na organização dos materiais semióticos que 
compõem esta obra) uma permanente disposição para a escuta, para o silêncio, para a perplexidade e para a pura observação-marcas registradas da inflexão crítica que as formas documentárias contemporâneas oferecem ao próprio jornalismo, enquanto atividade e discursividade.

\section{Referências}

ADAMS, Jeff. Documentary graphic novels and social reality. Bern: Peter Lang. 2008.

BAETENS, Jan. Revealing traces: a new theory of graphic enunciation. In VARNUM, Robin, GIBBONS, Christina T. (Org.): The Language of Comics: words and image. Jackson: University Press of Mississipi, 2001, p. 145-155.

BANITA, Giorgiana. Cosmopolitan suspiscion: comics journalism and graphic silence. In STERN, Daniel, DENSON, Shane and MEYER, Christina (Org.). Transnational perspectives on graphic narratives: comics at the crossroads. London: Bloomsbury, 2013, p. 49-66.

BARTHES, R.. L'analyse structurale du récit. Communications, no. 8, 1966, p. 1-27.

BENVENISTE, Émile. Problèmes de linguistique generale, 1. Paris: Gallimard, 1966.

BORDWELL, David. Neo-structuralist narratology and the functions of filmic storytelling. In RYAN, Marie-Laure (Org). Narrative across media: the languages of storytelling. Lincoln: Nebraska University Press, 2004, p. 203-219.

EL REFAIE, Elisabeth. Autobiographic comics: life writing in pictures. Jackson: University of Mississipi Press. 2012.

FRANÇA, Andrea. É possível conhecer a estória toda? Variações do documental e do tribunal nas imagens contemporâneas. FURTADO, Beatriz (Org.) Imagem contemporânea. vol II. Fortaleza: Hedra, 2009, p. $215-233$.

FRANÇA, Andrea; PICADO, Benjamim; LINS, Consuelo. Figuras da imersão visual do espectador na imagem: a construção dos "lugares da experiência" nas práticas documentais contemporâneas. In: Comunicação, Mídia e Consumo. São Paulo, no. 10, v. 28, 2013, p. 31-48.

GAUDRÉAULT, André; JOST, François. Le récit cinematographique. Paris: Nathan, 1990. 
GUIBERT, Emmanuel; LEFÈVRE, Didier; LEMERCIER, Frédedèric. The photographer (trad. Alexis Siegel). New York: First Second, 2009.

LINS, Consuelo. Le film-dispositif dans le documentaire brésilien contemporain. In : Cinémas. França, no. 22, v. 1, 2011 , p. 93-104.

LUGON, Olivier. Le style documentaire: d'August Sander a Walker Evans. Paris: Macula. 2004.

LUNSFORD, Andrea A; ROSENBLATT, Adam. "Down a road into an awful silence": graphic listening in Joe Sacco's Comics Journalism. In: GLENN, Chreyl; RATCLIFF, Krista (Org.). Silence and listening as rhetorical arts. Carbondalle: Southern Illinois University Press, 201 1, p. 130-146.

MARION, Philippe. Traces en cases: travail graphique, figuration narrative et participation du lecteur. Louvain-laNeuve: Academia, 1993.

METZ, Christian. L'énonciation impersonelle. Paris: Klincksieck, 1991.

PICADO, Benjamim. Sentido visual e vetores de imersão: regimes plásticos da implicação do espectador no fotojornalismo. Galaxia, São Paulo, no. 22, 2011 , p. 53-66.

PICADO, Benjamim. O Olho suspenso do novecento: plasticidade e discursividade visual no fotojornalismo moderno. Rio de Janeiro: Azougue/FAPERJ, 2014.

POIVERT, Michel. La photographie contemporaine. Paris: Flammarion, 2009.

ROSENBLATT, Adam; LUNSFORD, Andrea A.. Critique, caricature and compulsion in Joe Sacco's comics journalism. In: WILLIAMS, Paul; LYONS, James. The rise of the American comics artist: creators and contexts. Jackson: University of Mississipi Press, 2010, p. 68-89.

SCHAEFFER, Jean-Marie. Pourquoi la fiction? Paris: Seuil, 1999.

SCHAEFFER, Jean-Marie. Adieu à l'esthétique. Paris: PUF, 2000.

\section{Notas}

1 Talvez valha a pena relativizar esta caracterização de Sacco, destacando que a "escuta instrumental" define, segundo Lunsford e Rosenblatt, apenas a fase inicial de sua obra, tendendo a ceder espaço a outras modalidades de acolhimento que tipificam posturas mais abertas aos testemunhos alheios. Ainda assim, no contraste com Le Photographe, fica evidenciada uma predileção por registros mais "sensacionais" das situações de conflito (em Sacco), demarcando 
uma importante diferença com respeito às atitudes de escuta mais próximas daquelas encontradas em certas formas documentais contemporâneas (em Guibert, Lefèvre e Lemercier).

2 Destacamos que nos concentraremos apenas sobre o primeiro dos três volumes da obra, tendo em vista os limites espaciais para a apresentacão e desenvolvimento de nossa argumentação. Em oportunidades futuras, abordaremos os outros possíveis registros desta enunciação narrativa e gráfica, a partir do exame dos segmentos restantes de Le Photographe.

3 Sumariamos a história de Le Photographe: trata-se de um registro quadrinístico das peripécias do fotógrafo Didier Lefèvre, em seu trabalho de documentação visual da missão humanitária de uma equipe da organização Médicos Sem Fronteiras, no esforço de estabelecer postos avançados para o apoio e socorro médicos a comunidades atingidas pela guerra entre forças rebeldes e o exército soviético, na região norte do Afeganistão, em 1986.

4 Um bom apanhado das idéias do estruturalismo na análise fílmica, com sua subseqüente crítica, pode ser examinado em David Bordwell (BORDWELL, 2004).

Benjamim Picado é Doutor em Comunicação e
Semiótica, pela PUC-SP. Atuou de 1991 até 2009
como Professor do Departamento de Comunicação
da Universidade Federal da Bahia. Desde 2010 ,
é membro do corpo docente permanente do
Programa de Pós-Graduação em Comunicação da
Universidade Federal Fluminense. É pesquisador
associado (Fellow Researcher) do Centre of
Iberian and Latin American Visual Studies
(CILAVS), no Birkbeck College, em Londres,
Reino Unido. É autor do livro O Olho Suspenso do
Novecento: plasticidade e discursividade visual no
fotojornalismo moderno. Rio de Janeiro: Azougue/
FAPERJ, 2014. E-mail: jbpicado@hotmail.com

RECEBIDO EM: 25/02/2015 | ACEITO EM: 15/04/2015 